\title{
EL 'NATIVOHABLANTISMO' EN LA INVESTIGACIÓN DE LAS LENGUAS INDÍGENAS: EL CASO DEL MAPUDUNGUN EN CHILE
}

\author{
'NATIVESPEAKERISM' IN THE RESEARCH OF INDIGENOUS \\ LANGUAGES: THE CASE OF MAPUDUNGUN IN CHILE
}

\section{Marco Espinoza Alvarado*1}

\section{RESUMEN}

En este trabajo expando la noción de 'nativohablantismo' (o ideología del hablante nativo) y discuto su presencia e implicancias en algunas investigaciones acerca de la situación sociolingüística de la lengua mapuche en Chile. En los trabajos que discuto, se asume la ventaja del hablante nativo $(\mathrm{HN})$ de lengua indígena como investigador de fenómenos sociolingüísticos complejos, como el desplazamiento lingüístico, que afectan a grupos humanos también complejos. Argumento que este tipo de nativohablantismo, más que ser una alternativa teórico-metodológica para conceptualizar y estudiar la realidad sociolingüística, o ilustrar la emergencia de una epistemología propia y subalterna, solo contribuye a la creación de jerarquías intra e intergrupales, a la definición de relaciones de poder y a la disputa por la legitimidad en la generación de conocimiento. Así, este tipo de nativohablantismo, más que abrir posibilidades para pensar ciertas realidades sociolingüísticas de manera alternativa, desafiando la forma en que las hemos estudiado, limita nuestras maneras de conceptualizar estos problemas y perpetúa una visión esencialista, ahistórica y apolítica tanto de los procesos por los que atraviesan las lenguas y grupos minorizados como del aparato conceptual y metodológico con que se han estudiado. Los casos que discutiré, aunque reducidos, refieren a dos aristas no consideradas en el debate en torno al nativohablantismo (HN investigador / HN de lenguas indígenas) al mismo tiempo que revelan las paradojas presentes en torno a la politización de ciertas categorías en la lingüística: mientras que, por un lado, el concepto HN se desnaturaliza y deconstruye, por otro, se idealiza y fetichiza (MUNI TOKE, 2014c). Finalizo discutiendo las implicancias de este nativohablantismo en el contexto de las lenguas indígenas minorizadas en Chile y de la comprensión de su situación sociolingüística.

Palabras-clave: nativohablantismo; HN de lengua indígena; investigación lingüística.

\section{ABSTRACT}

In this paper I expand the notion of nativespeakerism (or ideology of the native speaker) and discuss its presence and implications in a few studies about the sociolinguistics of the Mapuche language in Chile. In these studies an assumption is made regarding the inherent advantages of the native speaker (NS) of an indigenous language as a researcher of complex sociolinguistic phenomena, such as language shift, that affect their own group. I argue that

\footnotetext{
* Universidad de Chile, Santiago, Chile.marcespi@uchile.cl, https://orcid.org/0000-0002-0568-0661 1.Agradezco a los dos correctores anónimos cuyas observaciones y consejos me ayudaron a mejorar la calidad de este trabajo.
} 
this type of nativespeakerism, rather than being a theoretical and methodological alternative for the conceptualization and study of sociolinguistic reality, or exemplifying the emergence of an indigenous and subaltern epistemology, works on an ideological dimension that only contributes to the creation of hierarchies between and within groups, to the definition of power relations, and to the dispute over the legitimacy in the production of knowledge. Thus, this type of nativespeakerism, rather than opening up alternative routes for thinking about sociolinguistic realities, challenging the way these have been studied, limits the ways in which we can conceptualize these phenomena and promotes an essentialist, ahistorical and apolitical view of the complex processes minoritized languages and groups are undergoing. The cases I will discuss, even though reduced in number, refer to two aspects not considered in debates around nativespeakerism (NS researcher / NS of indigenous languages), and, at the same time reveal the paradoxes around the politicization of certain linguistic categories: while the NS is deconstructed and criticized, it is also idealized and fetichized (MUNI TOKE, 2014c). I conclude the paper discussing the implications of this type of nativespeakerism in the context of minoritized indigenous languages in Chile and the study of their sociolinguistic situation.

Keywords: nativespeakerism; indigenous language NS; linguistic research.

\section{INTRODUCCIÓN}

El uso del concepto hablante nativo $(\mathrm{HN})$ y sus implicancias en diversos ámbitos de la lingüística aplicada han sido materia de debate en las últimas décadas. Es posible afirmar que este debate se ha concentrado y articulado más coherentemente como resultado de la expansión del inglés como lengua global (O'ROURKE \& PUJOLAR, 2013) y principalmente en torno a discursos y prácticas que involucran el concepto de $\mathrm{HN}$ de inglés en la enseñanza de dicha lengua. En este contexto, la crítica se ha focalizado en las consecuencias de lo que se ha denominado nativohablantismo (del inglés nativespeakerism, HOLLIDAY, 2006), el cual, a rasgos generales, consiste en la naturalización y normalización de la superioridad de un supuesto HN (principalmente occidental) como representante cultural, profesor, objetivo de aprendizaje y parámetro para la evaluación del desempeño de aprendientes de lenguas. En otras áreas de la lingüística aplicada, sin embargo, la problematización del $\mathrm{HN}$ ha sido más reciente (O'ROURKE \& PUJOLAR, 2013), como lo ilustran las discusiones en ámbitos tan diversos como la documentación lingüística (AMEKA, 2006), el análisis lingüístico para la determinación del origen de refugiados (CAMBIER-LANGEVELD, 2010; MUNI TOKE, 2011) y algunas investigaciones en contextos de lenguas minorizadas y de revitalización lingüística (DE KORNE, 2017; DOERR, 2009; MOORE et al., 2010; O'ROURKE \& PUJOLAR, 2013; O'ROURKE, PUJOLAR, \& RAMALLO, 2015), 
En este artículo me interesa expandir la comprensión del nativohablantismo y discutir su presencia e implicancias en un ámbito disciplinar específico y en un contexto diferente: algunas investigaciones en torno a la lengua mapuche en Chile. Así, este trabajo se conecta tanto con la discusión a nivel global del nativohablantismo en inglés como con problematizaciones más recientes del concepto $\mathrm{HN}$ en el campo de las lenguas minorizadas. El énfasis, sin embargo, es diferente. Los casos que discutiré, aunque reducidos, refieren a dos aristas no consideradas en el debate en torno al nativohablantismo (o ideología del $\mathrm{HN}$ ) al mismo tiempo que revelan las paradojas presentes en la lingüística como resultado de la politización de ciertas categorías. En los casos que presento, el nativohablantismo se manifiesta en la asignación, directa o indirecta, de superioridad/autoridad/legitimidad al HN en tanto investigador de fenómenos sociolingüísticos relacionados con la lengua de la cual se identifica (o es identificado) como HN (e.g., el desplazamiento lingüístico). Este $\mathrm{HN}$, a diferencia del $\mathrm{HN}$ de inglés que predomina en el debate tradicional, es hablante de lenguas indígenas minorizadas, el cual, en general, no suele ser problematizado y tiende a ser visto, desde una perspectiva esencialista, como representante claro, puro e inequívoco de su lengua, de su cultura y de su grupo/ comunidad. Este escenario, como mostraré, refleja una paradoja en la lingüística: mientras que, por un lado, el concepto HN (así como los discursos y prácticas asociadas) se desnaturaliza y deconstruye, por otro, se idealiza y fetichiza (MUNI TOKE, 2014c).

Desde un enfoque que se puede situar en la lingüística aplicada crítica (KABEL, 2009; PENNYCOOK, 1990, 2001; VIÁFARA, 2016), discutiré este uso particular del concepto (y rasgo identitario) HN por algunos investigadores en el estudio de algunos aspectos de la lengua mapuche. En un contexto en que la lingüística aplicada ha comenzado a debatir categorías que se han dado por sentadas (ZAVALA, 2018), uno de los objetivos de la lingüística aplicada crítica consiste en desmantelar "the ideological assumptions and professional doxa involved in applied linguistic practices, and a commitment to addressing issues of power, inequality and domination" (KABEL, 2009, p. 13). En los casos que discuto acá, la identidad bablante nativo-investigador de mapudungun es utilizado como dispositivo argumental final para asignar y asignarse autoridad para referirse a fenómenos culturales, políticos y sociolingüísticos complejos que atañen a grupos humanos también complejos. Esta movida discursiva tiene consecuencias en diferentes niveles sin contribuir necesariamente a una mejor comprensión de la situación sociolingüística de lenguas indígenas ni de lo que se requiere para su estudio y promoción. Más bien, el nativohablantismo que exploro en este trabajo, más que 
ser una manera diferente de conceptualizar la realidad sociolingüística (entre varias posibles) o ilustrar la emergencia de un pensamiento subalterno y propio, parece operar principalmente en una dimensión más política e ideológica que contribuye a la creación de jerarquías intra e intergrupales, a la definición de relaciones de poder y a la disputa por la legitimidad en la generación de conocimiento. En otras palabras, este tipo de nativohablantismo (el $\mathrm{HN}$-investigador), más que abrir posibilidades para pensar ciertas realidades de manera alternativa, o desafiar la forma en que las hemos estudiado, limita nuestra conceptualización de estos problemas y perpetúa una visión esencialista, ahistórica y apolítica tanto de los procesos por los que atraviesan las lenguas y grupos minorizados como del aparato conceptual y metodológico con que se han estudiado.

En lo que sigue, primero reviso las dificultades para definir al $\mathrm{HN}$ y discuto la ideología del nativohablantismo con el fin de caracterizar el contexto global en el que se enmarca esta discusión. Luego, describo brevemente el rol del HNinvestigador en lingüística, para, a continuación, discutir la manifestación y las implicancias del nativohablantismo en algunos estudios en torno al mapudungun. Por razones que explico en la sección correspondiente, dedico especial atención al trabajo de Painequeo y Quintrileo (2015). A continuación, a través de un ejemplo, discuto la manera en que el trabajo etnográfico pone en entredicho las supuestas ventajas presentes en categorías a priori tales como $\mathrm{HN}$-investigador. Concluyo enfatizando los puntos centrales de mi discusión y reflexionando acerca de las implicancias de este nativohablantismo, aún incipiente y reducido, en el contexto del estudio de la situación de las lenguas indígenas en Chile.

\section{EL HABLANTE NATIVO Y EL NATIVOHABLANTISMO}

\subsection{Hablante nativo: concepto elusivo y categoría lingüística en entredicho}

La dificultad para definir el concepto $\mathrm{HN}$ e identificar su referente incontrovertible (ANEJA, 2014; LOWE 2016; PAIKEDAY, 1985a; WELLS \& PAPPENHEIM, 1996, entre otros) contradice la facilidad con que aún se le suele utilizar en lingüística. El HN ha sido sometido a bastante revisión y crítica por lo menos desde el trabajo de Paikeday (1985a, 1985b), a tal punto que su utilización en la discusión de una serie de fenómenos (socio)lingüísticos ha sido puesta en entredicho (BELTRÁN, 2000; COOK, 1999; DAVIES, 1991, 2003; ESPINOZA, 2015; FALLAS, 2016; MAY, 2013; MUNI TOKE, 2014c; ORTEGA, 2013; 
WIDDOWSON, 2012). Los críticos del término apuntan, entre otros aspectos, a su ambigüedad e inconsistencia (VIÁFARA, 2016) y al sesgo monolingüe que conlleva (BRAINE, 2010; CANAGARAJAH, 2007; COOK, 1999; LIDDICOAT, 2016; MUNI TOKE, 2014c; OLATE, 2017; ORTEGA, 2013). Para algunos autores, el HN y su opuesto, hablante no-nativo, son categorías popularizadas profesionalmente que no se sustentan tan firmemente, como se quisiera creer, sobre bases científicas, lingüísticas o de nacionalidad (HOLLIDAY, 2015; MUNI TOKE, 2014c). Corresponderían, más bien, a suposiciones institucionalizadas, junto a otras como lengua materna, comunidad monóglota (KRAVCHENKO, 2010) o lengua del hogar (bome language) (BLOMMAERT, 2017). En otras palabras, HN sería una entidad postulada (WAWRZYNIAK, 2010) para dar coherencia a ciertos discursos académicos especializados (así como sustento a la ideología del estado-nación, BONFIGLIO, 2010; MUNI TOKE 2014c; O'ROURKE \& PUJOLAR, 2013).

Esta crítica al $\mathrm{HN}$ también puede ser entendida en términos de un movimiento desde la idealización del concepto a su politización (MUNI TOKE, 2014c). Según esta autora, esta politización se refiere a un proceso que lleva a considerar a la categoría HN como portadora de ideologías políticas acerca del lenguaje. Como resultado, se le resta relevancia científica al término al enfatizarse su dimensión ideológica (MUNI TOKE, 2014c; ver también ANEJA, 2014).

En este contexto, las propuestas extremas apuntan a eliminar el concepto HN de las herramientas de la lingüística aplicada y de la sociolingüística, por corresponder a una clasificación a priori y por ser una idealización y un concepto lingüísticamente inútil que casi no tendría valor explicativo (BLOMMAERT Y RAMPTON, 2011; HOLLIDAY, 2015; PILLER, 2001). Esto no ha impedido, sin embargo, que el concepto $\mathrm{HN}$ aún goce de relativa buena salud en estas disciplinas.

En suma, a pesar de no poseer una definición y referente claros, el concepto $\mathrm{HN}$ se emplea como si se tratase de una categoría natural que se da por sentada. Se asume que su uso no planteará la menor controversia o extrañeza y que no tendrá repercusiones ${ }^{2}$. Sin embargo, $\mathrm{HN}$ es una categoría complicada que no refiere a una realidad claramente delimitada y que, por lo mismo, difícilmente puede llamar a acuerdo. Su uso será, por lo tanto, desde una perspectiva crítica, necesariamente controversial. Tal controversia, sin embargo, no debe ser reducida a una cuestión

2. Tal vez una de las pocas excepciones a esta tendencia por evitar definir HN la constituye CambierLangeveld (2010) quien, en su trabajo acerca del rol de los HN y los lingüistas en el análisis lingüístico para la determinación del origen de refugiados, entrega su definición de lo que entiende por $\mathrm{HN}$ en tal contexto. Esta definición explícita es discutida y cuestionada en algunos de sus aspectos por Muni Toke (2011). Este caso es, precisamente, un ejemplo de la controversia que genera la referencia al hablante nativo. 
terminológica (MUNI TOKE, 2014c) o de dificultad para encontrar un referente. Más bien, las reacciones que genera el uso del concepto HN (incluso como rasgo identitario) se enfocan en sus consecuencias ideológicas y sus implicancias teóricas, metodológicas, políticas, epistemológicas y prácticas ${ }^{3}$.

\subsection{Consecuencias ideológicas: el nativohablantismo}

El debate en torno al HN, si bien presente en otras disciplinas, ha cobrado mayor fuerza y se ha articulado teórica y metodológicamente de manera más consistente en diversos ámbitos de la lingüística aplicada y de la enseñanza de inglés, donde se ha postulado que su uso expresaría una ideología particular: el nativohablantismo (HOLLIDAY, 2005, 2006). En el centro de esta controversia está la legitimidad, autenticidad, superioridad y autoridad innata asignada al HN, de lo cual algunos autores responsabilizan a las ideas chomskianas en torno al hablante-oyente ideal en una comunidad monolingüe homogénea (por ejemplo, CANAGARAJAH, 1999; RAMPTON, 1990; VIÁFARA, 2016). Esta crítica al HN (y a la norma nativa) se realiza, además, en un contexto mayor donde lo que está en entredicho es el sesgo monolingüe que ha caracterizado a la investigación en lingüística aplicada (MAY, 2013).

A riesgo de simplificar, es posible afirmar que el nativohablantismo se entiende en este contexto como un conjunto de creencias, actitudes y predisposiciones que llevan a considerar, sin base empírica alguna, a los HN (por ejemplo, de inglés) como representantes de una cultura (por ejemplo, occidental) de la cual nacen prácticas y metodologías de enseñanza avanzadas y como modelos de una gramática y pronunciación correctas, ideales o prestigiosas (HOLLIDAY, 2005, 2006, 2015; LOWE \& KICZKOWIAK, 2016; SWAN, ABOSHIHA \& HOLLIDAY, 2015). Igualmente, se consideraría al $\mathrm{HN}$ como el objetivo lingüístico incuestionable al cual los aprendientes de lengua debiesen siempre aspirar y como el estándar legítimo para evaluarlos e investigar su desempeño (ESPINOZA, 2015).

Las reacciones al nativohablantismo en el contexto del inglés como lengua global, más que enfocarse en el $\mathrm{HN}$-investigador, apuntan fundamentalmente a develar las consecuencias negativas bastante reales que esta ideología tiene en la

3. Al lector interesado, recomiendo la lectura de Waters (2007), quien se opone a quienes toman una postura crítica respecto del uso del concepto $\mathrm{HN}$, argumentando que tales propuestas adolecerían de fallas epistemológicas y metodológicas serias, y que lo mejor es continuar utilizando aproximaciones más tradicionales pero aún valiosas. Esto le valió una respuesta de Kabel (2009), quien acusa a Waters de naturalizar y neutralizar ideológicamente los estereotipos y el nativohablantismo. Este es un interesante ejemplo del debate entre las posiciones más positivistas (supuestamente neutrales y objetivas) y los enfoques críticos en la lingüística aplicada. 
percepción y evaluación de las habilidades de profesores y de hablantes no-nativos de dicha lengua. Sin embargo, como mostraré, es posible hacer un paralelo entre los fundamentos que subyacen a este tipo de nativohablantismo y el expresado en la posición $\mathrm{HN}$-investigador que acá discuto. En ambos casos las ventajas del HN serían innatas y se asociarían a su supuesta pertenencia privilegiada al grupo, el cual es concebido como homogéneo, monolingüe, y con una cultura y territorio estables.

Además de esta esencialización de las fortalezas de los HNs, típica del nativohablantismo (LOWE \& KICZKOWIAK, 2016), ambos tipos de nativohablantismo también comparten la característica más inherente, y que se desprende de este esencialismo, a saber, la incredulidad o desconfianza cultural (cultural disbelief), definida originalmente como incredulidad respecto de la contribución cultural de profesores etiquetados como hablantes no-nativos (HOLLIDAY, 2015, p. 11). Esta desconfianza se puede resumir en la fórmula "the 'Others' really can't do it as well as 'Us'" (SWAN et al., 2015, p. 1). Para Holliday $(2015$, p.16) "Once a particular group of people, defined upon cultural or linguistic grounds, are demarcated as able or unable to carry out certain tasks by virtue of this native-speakerist imagery, an ethos of discrimination is set up which impacts on all parties". Como mostraré, esta desconfianza cultural, originalmente asignada a profesores no-nativos, también la despliegan algunos de los $\mathrm{HN}$-investigadores que discuto en este ensayo. Finalmente, polémicas referentes a la autoridad, legitimidad y prestigio de los $\mathrm{HN}$ y que están en la base de la crítica al nativohablantismo en inglés, también rondan contextos de lenguas minorizadas y de revitalización lingüística (ver, por ejemplo O’ROURKE \& PUJOLAR, 2013) y, en este caso, de investigación en lenguas indígenas.

El nativohablantismo oculta que el uso de la categoría $\mathrm{HN}$ para autodescribirse o describir a otros, ya sea como profesor o como investigador, remite a connotaciones positivas (BRAINE, 2010) y no es neutro, ya que adquiere su carga semántica, valórica, estética, política y epistemológica en contraposición a hablante no-nativo (ORTEGA, 2013), el cual es construido como el otro y ocuparía el polo negativo de la distinción, refiriéndose, en la mayoría de los casos, a lo deficiente (BONFIGLIO, 2010; HOLLIDAY, 2006, 2015). El nativohablantismo no es necesariamente promovido por todos quienes se autoidentifican como HN de una lengua y también puede ser fomentado por los así llamados hablantes nonativos (HOLLIDAY, 2006).

Esta controversia en torno al nativohablantismo nos recuerda que aquellas discusiones o planteamientos que recurren al HN como soporte argumentativo central (en tanto concepto o rasgo identificatorio) deben ser analizados como 
posibles instancias de la construcción discursiva de la otredad (BONFIGLIO, 2010) y del déficit, la diferencia, la discriminación y la dominación (PILLER, 2001). En el ámbito de la investigación lingüística, el concepto $\mathrm{HN}$, así como su contraparte hablante no-nativo, "ofrece un punto de entrada útil para comprender la manera en que las ideologías lingüísticas funcionan en el conocimiento disciplinar" (ORTEGA, 2013, p. 34).

Antes de discutir el nativohablantismo en algunas investigaciones en torno a la lengua mapuche en Chile, describiré brevemente al rol asignado al investigador $\mathrm{HN}$ de lengua indígena en lingüística.

\section{EL INVESTIGADOR HN DE LENGUA INDÍGENA EN LINGÜÍSTICA}

En lingüística, la formulación más explícita de que la condición de HN de lengua indígena es favorable para la investigación puede ser rastreada en el trabajo de Hale (1972). En el contexto de la documentación, descripción y elaboración de gramáticas de las lenguas nativas de Norteamérica, Hale consideraba que los avances dependerían de lingüistas hablantes nativos de dichas lenguas, ya que ellos poseerían la competencia nativa y las intuiciones lingüísticas de carácter chomskiano (o el conocimiento metalingüístico, de acuerdo con HIMMELMANN, 2006) a las que lingüistas hablantes no-nativos no podían aspirar. Estos últimos solo tendrían un acceso incompleto a los datos necesarios para una adecuada descripción de la lengua. Sin embargo, Hale también reconocía que la competencia no lo era todo y que las habilidades en análisis lingüístico también eran fundamentales. Así, el escenario ideal para Hale consistía en que el $\mathrm{HN}$ de la lengua indígena (la fuente de los datos) y el lingüista (el analista de dichos datos) fuesen la misma persona. Estas ideas luego son revisitadas y reforzadas por diversos autores dos décadas más tarde en el número especial de la revista Language (1992) dedicada a las lenguas en peligro y a la salvaguarda de la diversidad lingüística (HALE et al., 1992).

El ámbito de acción en este contexto se enmarcaba principalmente en la descripción de la lengua como sistema (la gramática). Sin embargo, elaboraciones posteriores van más allá y proponen otros beneficios al hecho de ser HN de lengua indígena y lingüista, y que son relevantes para la discusión que planteo. Un claro ejemplo es England (2012) para quien

[indigenous] native speaker linguists are at the same time members of a minority language community and also linguists; they may have a greater ability to apply linguistics to practical problems related to language, communication, and education than would outsiders. Advanced study in linguistics gives them added authority with regard to language-related policy issues and also the real knowledge from which to make policy-related decisions. Finally, the 
prestige that accrues to the language itself when speakers become linguists is of real value in contributing to language maintenance (2012, p. 13).

Si bien en las formulaciones anteriores de la ventaja del HN-investigador se podían aceptar los supuestos en los argumentos propuestos por Hale y otros lingüistas ${ }^{4}$, los supuestos en la afirmación de England son más difíciles de aceptar sin oposición. Esto, no solo porque simplifica la relación de los hablantes y de los expertos con sus propias comunidades, sino que también porque ignora las diferencias y complejidades políticas e ideológicas presentes especialmente en comunidades minorizadas (MOORE et al., 2010), a la vez que refuerza mitos como el del conocimiento total que un miembro de una comunidad tiene de ella y el de la contribución al prestigio de la lengua y a la mantención lingüística que se manifestaría solo por el hecho de ser algunos miembros de la comunidad lingüistas. Sin embargo, la cita contiene los elementos esenciales para promover el nativohablantismo en la investigación: el HN lingüista posee mayor habilidad, autoridad, conocimiento real y prestigio (las mismas características asignadas al HN profesor). Por otro lado, los ejemplos que ofrece England (2012) de las contribuciones de los HN lingüistas se remiten a descripciones de la estructura de las lenguas indígenas, en ningún caso a trabajos relacionados con los asuntos prácticos, educacionales y de planificación lingüística mencionados en la cita.

A estas aseveraciones de England se puede aplicar la crítica al discurso de las lenguas en peligro. Según esta crítica, dicho discurso "draws on and perpetuates naïve Western assumptions about languages as bounded denotational codes, each with a formally stable reality and a naturalised inherence in an ethnic group, often one that is typically conceived of as culturally grounded in a unique 'ecological niche'" (DOBRIN, AUSTIN \& NATHAN, 2009, p 38). Apelar al HN contribuye a reforzar tales supuestos simplificadores acerca de las lenguas, las comunidades y los procesos sociolingüísticos por los que atraviesan.

\section{EL HABLANTE NATIVO-INVESTIGADOR: EL CASO DE LA LENGUA MAPUCHE}

En el contexto chileno el nativohablantismo expresado en el $\mathrm{HN}$-investigador, aunque no es una tendencia instalada, se ha desplegado de diversas maneras. Los

\footnotetext{
4. Aunque no sin dificultad. Como indica Ameka (2006, p. 1) "it has become increasingly clear [en la documentación lingüística] that there are different kinds of native speakers" de lenguas indígenas o en peligro. Ver también la discusión presentada por Evans (2001). Por otro lado, nada garantiza que el HN lingüista tenga acceso a todos los contextos y eventos comunicativos de la comunidad, lo que significa que su registro, especialmente sociolingüístico, también puede estar incompleto.
} 
pocos casos que discuto a continuación corresponden a estudios en torno a algunos aspectos sociolingüísticos de la lengua mapuche, más que a su estructura lingüística.

En su estudio, Lara Millapan (2012) se autodesigna HN de mapudungun pero no define tal categoría o condición, considerando, además, que claramente estamos en presencia de un sujeto bilingüe. La autora explica que debido a que todos sus entrevistados eran HN de mapudungun, "la investigadora siendo también hablante nativa de esta lengua, ha decidido realizar la entrevista en mapudungun, pues se facilita la comunicación y los conocimientos que se generan se presentan de forma más completa" (2012, p. 33). Esta es sin duda una decisión metodológica sensata, en tanto se acomoda a las habilidades comunicativas de los entrevistados. Sin embargo, el nativohablantismo se manifiesta inmediatamente a continuación cuando observa que esto le permite entender "los elementos culturales, sociales e ideológicos imperantes en cada lengua para su cultura de pertenencia" (2012, p. 33). Así, construye la superioridad del HN-investigador apelando a una suerte de relativismo lingüístico que solo un investigador $\mathrm{HN}$ de la lengua en cuestión podría capturar. Esto, sin embargo, no influye ni determina ningún aspecto del diseño y la realización de la investigación, ni tampoco de la interpretación de los datos recogidos $^{5}$. De hecho, respecto de la información entregada en mapudungun por los entrevistados, simplemente explica que "estas opiniones fueron interpretadas a la lengua castellana por parte de la investigadora" $(2012$, p. 33), dando a entender que no hubo ningún problema serio en el proceso de traducción. En otras palabras, simplemente diluye la especificidad expresiva asignada a la lengua mapuche y la cual solo podía ser capturada por la investigadora $\mathrm{HN}$.

Si alguna facilidad existió para esta investigadora en algunos aspectos de su investigación (específicamente la recolección de datos), esta se debió, más que a su calidad de HN, a su cercanía con algunos de los entrevistados, lo que le permitió incluso pasar por alto lo que ella misma denomina protocolos "desde el contexto de la cultura mapuche" $(2012$, p.33). Así, mientras que las entrevistas realizadas a unas autoridades tradicionales se realizaron sin cámaras ni grabadoras "por respeto a sus ${ }^{6}$ creencias ancestrales" (2012, p. 33), las entrevistas a otras autoridades ancestrales sí incluyeron el uso de una videocámara ya que estas autoridades "eran personas del ámbito de la investigadora" por lo que accedieron sin problemas a ser grabados (2012, p. 33).

5. Por ejemplo, la autora no entrega datos de la comunidad específica en que llevó a cabo su estudio y solo hace mención a la situación sociolingüística general mapuche.

6. Nótese el uso de "sus" que instala una distancia entre la investigadora y sus participantes, cuestión contradictoria al ella misma denominarse mapuche hablante nativa y apelar, por lo tanto, a la pertenencia al grupo. 
Otro ejemplo de la ventaja del $\mathrm{HN}$-investigador, la cual es atribuida de manera relativamente indirecta, lo encontramos en Teillier et al. (2016, p.137) donde, en una nota a pie de página, se nos dice que "De acuerdo con el Dr. (c) [nombre de uno de los autores del artículo], hablante nativo altamente competente y coautor de este artículo, mapunzugun es el nombre apropiado para la lengua; la palabra mapuzugun, en cambio, se vincularía con conflictos de tierra y no con el nombre de ella" (cursivas y destacado en el original). Acá encontramos una serie de movidas discursivas comunes en argumentos que se apoyan en el HN.

En primer lugar, se utiliza el concepto $\mathrm{HN}$ sin definirlo y como característica identificatoria incontrovertida (cuando nuevamente estamos en presencia de un sujeto bilingüe). En segundo lugar, se construye una jerarquía bastante problemática de hablantes nativos, donde al autor se le ubica en la categoría "altamente" competente, sin especificar en relación a qué parámetro o comunidad específica. Esto revela que incluso en aquellos grupos que apelan a la categoría HN se marcan jerarquías intragrupales de tipos de hablantes que remiten a capacidades y autoridad (O’ROURKE \& PUJOLAR, 2013). Así, no es suficiente ser HN ni competente, sino que se debe ser "altamente" competente. En tercer lugar, se le vuelve a diferenciar de los otros HN (suponemos incluso de otros altamente competentes) por el hecho de ser especialista en lingüística, lo que, en el fondo, equivale a decir que no basta con ser HN altamente competente. En otras palabras, no todos los HN son iguales. Son estas características en conjunto las que le permitirían a este HN zanjar el debate en torno al nombre correcto de la lengua. En ningún momento es posible inferir que tal certeza se haya desprendido de algún otro tipo de reflexión, como, por ejemplo, la presentada por Catriquir (2007) a quien no incluyen en sus referencias a pesar de coincidir en la misma denominación de la lengua, o de trabajo etnográfico con otros hablantes en diversas comunidades.

El carácter ideológico (no neutral) de tal aseveración quedaría demostrado si, por ejemplo, se preguntara por el nombre de su lengua a un HN medianamente competente (suponiendo que tal categoría pudiese ser establecida empíricamente) sin estudios lingüísticos, o a otros hablantes de mapudungun con formación académica en lingüística ${ }^{7}$. Otros investigadores mapuche utilizan diversas denominaciones. Rumian (2011) habla de che sungun para referirse a la variante regional huilliche.

7. En Butalelbun, la comunidad en la que realicé mi investigación doctoral y en la que continúo realizando trabajo de campo, la gente se debatía entre chedungun, mapudungun, o mapuche. Tendía a predominar la primera denominación, que es, además, la que utilizan investigadores no indígenas (HENRÍQUEZ, 2017; HENRÍQUEZ \& SALAMANCA, 2012). Becerra (2017, p. 127) nos indica que "La lengua mapuche, [es] denominada mapudungun o chedungun por sus hablantes" y que "Se reconocen también otras formas de nombrar la lengua (por ejemplo, mapuchedungun, tsesungun), que representan variantes dialectales, y de registrarla (por ejemplo, mapudungún, mapudungun), las cuales se relacionan al uso de distintos grafemarios y/o a la incorporación de la palabra al castellano". 
Nanculef (2016) utiliza mapuzugun. Lara Millapan (2012), Moulian y Catrileo (2013), Painequeo y Quintrileo (2015), y Quintrileo y Quintrileo (2018) utilizan mapudungun. Loncon (2017), apelando a la diversidad regional e identidades territoriales, y haciendo referencia a investigaciones previas entrega los siguientes nombres: chedungun, mapudungun, mapuchedungun, mapuzugun, y tse sumun. En ningún momento menciona mapunzugun. Naqill (2016) explica que "Mapudungun con " $\mathrm{d}$ " es la forma que utiliza el alfabeto Unificado. Mapuzungun, por su parte, incorpora la " $z$ " del alfabeto Ragilew, pero conserva la "ng" del Unificado" y agrega "Estos usos que provocan confusión y duda a quienes comienzan a acercarse a la lengua, es lo que tiene que resolverse a través de la estandarización", en otras palabras, a través de un proceso de deliberación conjunta y planificación lingüística. Entonces, si se acepta la propuesta del HN altamente competente especialista en lingüística, estos otros autores se equivocan. Si aceptamos las propuestas de estos otros autores, entonces se equivoca el $\mathrm{HN}$ en Teillier, pero ćquién se beneficia de este debate y en qué ayuda a comprender la situación sociolingüística de comunidades indígenas? Este tipo de nativohablantismo pretende imponer la idea de que determinada realidad política y sociolingüística puede ser fácilmente representada, comprendida y zanjada por un individuo como resultado de una característica particular, ignorando la pluralidad de voces tanto dominantes como subalternas presente, también, en comunidades indígenas (LOERA, 2018).

El uso de la categoría HN altamente competente en este caso, oculta que "incluso en aquellas zonas aparentemente más "objetivas y técnicas" de la lengua lo político tiene lugar, evidenciando que lo lingüístico está ... atado a las relaciones de poder que involucran a los sujetos y a las comunidades de habla" (ÁLVAREZ-SANTULLANO, FORNO \& RISCO DEL VALLE, 2015, p. 113). Son estas relaciones de poder y creación de jerarquías, incluso entre los mismos autodenominados $\mathrm{HN}$ y grupos indígenas minorizados, las que el nativohablantismo pretende ocultar.

Sin embargo, y en un giro interesante, en un artículo posterior los mismos autores (TEILLIER et al., 2018) reformulan y expanden su explicación, indicando que

De acuerdo con nuestra propuesta, mapunzugun sería la palabra apropiada para referirse a la lengua; mapun implica lo propio... Mapuzugun se refiere a conflictos de tierra, no ... a la lengua... Las personas cuando iban a los juzgados u otras instituciones propias de la cultura dominante, ... lo hacían por reclamos relacionados con la pérdida de tierras. En ese sentido hablaban sobre un asunto de tierras (mapuzugun) y debido a esto se entendió, de manera errónea, que esta era la denominación de la lengua (2018, p. 100). 
Lo interesante de este caso es que en este artículo ya no se apela al HN altamente competente experto en lingüística para decidir el nombre de la lengua, más bien se habla de "nuestra propuesta" y se propone una explicación histórica. Esta movida refleja lo ambivalente que es la simple apelación a la categoría HNinvestigador para zanjar cuestiones que atañen a la lengua, incluso para quienes se designan a sí mismos $\mathrm{HN}$.

El caso más complejo de nativohablantismo, y que originalmente motivó las reflexiones que acá presento, se encuentra en Painequeo y Quintrileo (2015). El trabajo de estos autores merece un análisis separado en mayor detalle que expongo a continuación.

\subsection{El HN investigador y el nativohablantismo en Painequeo y Quintrileo (2015)}

En su artículo de 2015, titulado "Algunas causas que podrían estar incidiendo en el eventual debilitamiento de la vitalidad y posible desplazamiento de la lengua mapuche por el castellano en Cbile", estos autores plantean un análisis crítico de algunos estudios acerca de la situación de la lengua mapuche y apuntan a entregar elementos para la comprensión de su desplazamiento. Su crítica más contundente es hacia los trabajos de Gundermann et al. (2009 y 2011).

Otro objetivo de los autores es presentar una visión nueva, la del HN, a la situación de la lengua mapuche en Chile. Estos autores dicen pensar y enunciar como un sujeto investigador al que llaman de diversas formas: "el hablante nativo de mapudungun, pero con manejo bibliográfico", "hablantes de la lengua mapuche y estudiantes de lingüística", "[observaciones desde una perspectiva] bilingüe como investigador nativo hablante de la lengua mapuche" (p. 207) ${ }^{8}$. Según estos autores, dicho tipo de investigador vendría a ofrecer una perspectiva nueva al estudio del desplazamiento lingüístico del mapudungun, además de posibilidades para su reversión (p. 207) .

8. Por razones de espacio no podré discutir esta imposición de uniformidad expresada en el uso del artículo "la", en la expresión "la" lengua mapuche, y que parece ser problemática. Por ejemplo, refiriéndose al habla de un niño que dice flusa en vez de blusa, nos dicen que esto ocurre "por cuanto en [el mapudungun] no existe el fonema /b/, de allí que lo sustituyó por el fonema /f/ que sí está en su sistema" (p. 212). Sin embargo, esta es una de las distinciones que a menudo me corrigen los hablantes de la comunidad con la que trabajo cuando mencionan que en otras comunidades "se ocupa más la efe", así, lo que en otras comunidades es tïfa en la comunidad es tïba (ver también HENRÍQUEZ, 2017).

9. De manera similar, pero en un contexto diferente, Aidle-SantaMaria (1992) introducía su trabajo de la siguiente manera: "This paper is an overview of topics ... from the perspective of a native speaker of an indigenous language and member of a university academic community" (p. 129). 
En las siguientes subsecciones muestro la manera en que el nativohablantismo se manifiesta en este artículo. Quisiera destacar que segmentos importantes (tal vez los centrales) de este artículo de 2015 ya habían sido publicados textualmente por los mismos autores en un trabajo de 2010. En dicho trabajo de 2010, sin embargo, planteaban el análisis de los mismos datos desde una perspectiva que llamaban sociocultural oralista y educacional y en ningún momento desde la perspectiva del HN-investigador. El trabajo de 2015, entonces, se podría interpretar como un giro epistemológico derivado de una particular adscripción identitaria.

\subsubsection{Nosotros y ellos}

Apelando a un recurso bastante común en los estudios que se valen del concepto HN, estos autores naturalizan su uso, dándole un estatus de sentido común, esperando que no nos extrañemos de él y que demos por sentado su significado y validez para (y en) el debate. A pesar de esto, el HN-investigador estos autores lo construyen implícitamente en una red de distinciones a través de las cuales crean una otredad (HOLLIDAY, 2006; BONFIGLIO, 2010). Las distinciones implícitas parecen ser: 1) nosotros -los lingüistas hablantes nativos de mapudungun- y ellos (los otros) -los lingüistas no hablantes de mapudungun-; 2) nosotros -los mapuche hablantes nativos de mapudungun-y ellos -los mapuche hablantes no-nativos de mapudungun-; y 3 ) nosotros -los hablantes nativos, pero con formación lingüísticay ellos -los hablantes nativos sin esa formación. Esta última distinción es interesante por cuanto supone precisamente una crítica a la idea de que ser $\mathrm{HN}$ es suficiente para pronunciarse respecto de cuestiones que atañen a la situación de la lengua del grupo. Esto se expresa en el uso de la conjunción en "el hablante nativo de mapudungun, pero con manejo bibliográfico" (p. 207). Esta es una contradicción que los autores no logran resolver.

A pesar de esta última distinción que pudiera parecer disonante, y considerando que este tipo de texto se distribuye en el ámbito académico, es su calidad de HN la que prima. Esto se manifiesta en la expresión "hablantes de la lengua mapuche $y$ estudiantes de lingüística" que indica la suma de ambas características (p. 207). En otras palabras, no basta con ser estudiante de lingüística, se requiere de algo más, en este caso, ser HN. Es, en definitiva, el "investigador nativo hablante de la lengua mapuche" (p. 207).

Aunque dicho trabajo no es en nada diferente del realizado por hablantes 'no-nativos', demuestra que la idea de una epistemología del $\mathrm{HN}$ de lengua indígena investigador es parte de cierto sentido común en sociolingüística. 
Estos autores nos explican que el ser $\mathrm{HN}$ les entrega competencias y conocimientos para responder ciertas preguntas y ofrecer soluciones. No especifican, sin embargo, cuáles (de todas las preguntas que plantean en su introducción) serían aquellas que están "más cerca de nuestras competencias por el becho de ser [léase en primer lugar] hablantes de la lengua mapuche y [en segundo lugar] estudiantes de lingüística" (p. 207) (cursivas mías). Además, nos indican que las observaciones que se hacen del desplazamiento lingüístico desde esta perspectiva del $\mathrm{HN}$ “... revelan que existen posibilidades para la reversión lingüística del mapudungun" (p. 207). En este punto, se podría argumentar que destacan la oposición con los investigadores no hablantes, quienes, debido a esa condición, supuestamente enfatizarían el desplazamiento ${ }^{10}$.

\subsubsection{La autenticidad del HN}

Los autores establecen su identidad como auténticos HN (a pesar de ser bilingües) a través de una serie de recursos textuales. En su autodescripción, ellos son, en primer lugar, hablantes de la lengua mapuche, y, en segundo lugar, estudiantes de lingüística. Cuando se refieren a los entrevistadores en el trabajo de Gundermann et al. los describen, en primer lugar, como entrevistadores y, solo en segundo lugar, como "hablantes de mapudungun" (p. 209), entiéndase no nativos, ya que para esto existe, precisamente, la expresión hablante nativo. Ignoran, sin embargo, el componente étnico en la descripción utilizada por Gundermann et al., quienes nos dicen que en su trabajo participaron "entrevistadores mapuches hablantes del mapuzugun" (GUNDERMANN et al. 2009, p. 39) ${ }^{11}$.

10. Según Painequeo y Quintrileo existiría una "opinión intelectual mayoritaria", que apuntaría "hacia una sola y desalentadora conclusión: la desaparición y el reemplazo de...el mapudungun por el castellano" (P. 207). Sin embargo, no todas las opiniones académicas apuntan a esta conclusión. Por ejemplo, Wittig $(2009,2011)$ propone que en contextos urbanos existen prácticas lingüísticas (como el aprendizaje del mapudungun como L2) que permitirían vislumbrar un horizonte más esperanzador. Teiller (2013), en tanto, plantea que "en el ámbito rural, el mapudungun no es una lengua en retroceso sino que se mantiene en el nivel mínimo 4(b) [de acuerdo a la escala de Fishman] necesario para ser considerada una lengua vital..., el grado de vitalidad del mapudungun en los territorios mapuches que poseen un grado de organización sociocultural propia es alto: $78,5 \%$ de hablantes" (p. 67). Además, una lectura de los autores revisados por Painequeo y Quintrileo, así como de otros estudios, no permiten llegar a esa interpretación sin matices que proponen para toda la lengua mapuche. Más bien, todo parece sugerir que cualquier generalización respecto de la situación sociolingüística del mapudungun debe ser tomada con precaución. Algo que ya habían advertido Duran y Ramos (1989) y Chiodi y Loncon (1999).

11. Esta referencia a la etnicidad de los entrevistadores en Gundermann et al. también puede ser interpretada como un intento por establecer una autoridad y legitimidad que se desprendería de la autenticidad étnica de los entrevistadores, i.e., son mapuches. Esto, indirectamente, daría validez a la medición de competencia que hacen y al instrumento que utilizan y, por ende, a los resultados e interpretaciones. La omisión por parte de Painequeo y Quintrileo de esta característica les permite esquivar convenientemente las complejidades que este hecho plantea para el debate. 
Se puede ver, además, que el uso de comillas por parte de Painequeo y Quintrileo en la expresión "hablantes de mapudungun" no corresponde a cita textual (no hay referencia a página y Gundermann et al. ocupan el glotónimo mapuzugun). El uso de este recurso nos alerta del sentido especial que los autores le quieren dar a esa expresión en este contexto, de lo contrario, habrían utilizado la forma no marcada sin comillas. Es dable inferir, por lo tanto, que los entrevistadores de Gundermann et al., en realidad, no son hablantes (esta inferencia se verá reforzada más adelante). Todo esto les permite a Painequeo y Quintrileo naturalizar su competencia superior como hablantes legítimos (BOURDIEU \& THOMSON, 1991) respecto de los entrevistadores en Gundermann et al. y así sentar las bases para referirse a ciertos temas sociolingüísticos complejos (el desplazamiento lingüístico).

\subsubsection{La superioridad del HN}

Por lo que se desprende del análisis que hacen a una pequeña muestra de las entrevistas en el trabajo de Gundermann et al., el HN que ellos representan también se caracterizaría por poseer una competencia lingüística superior y por representar un habla estandarizada, apropiada y correcta, a diferencia de "la forma extraña de hablar el mapudungun del entrevistador", la que confundía a los entrevistados ( $\mathrm{p}$. 211). Esto último lo aseveran a pesar de no haber estado en dichas entrevistas.

Estas ideas se refuerzan a través de una serie de afirmaciones (acá destaco con cursivas aquellos segmentos del extracto que avalan las interpretaciones que presento). Por ejemplo, cuando interpretan y tratan de traducir al castellano una pregunta en mapudungun hecha por el entrevistador en Gundermann et al., nos dicen "Con mucho esfuerzo y siendo bastante benevolente, podría traducir esta expresión como "donde este llamado cordillera de los Andes", pero en ningún caso la traducción que se da en el texto, a menos que baya babido un error tipográfico" (p. 211). En su artículo de 2010, los autores se refieren a este mismo segmento pero su análisis en ningún momento se realizó desde la perspectiva del HN (PAINEQUEO \& QUINTRILEO, 2010, p. 220). Otro ejemplo se da cuando caracterizan ciertos usos de los entrevistadores: "Luego, aunque en la segunda pregunta el entrevistador sí incorpora el verbo müley, extrañamente emplea los demostrativos tüfa" (p. 211).

Además, se atribuyen la capacidad para evaluar el desempeño lingüístico de otro hablante (los entrevistados en Gundermann et al.) sin haber participado directamente en la interacción, incluso al punto de explicar sus estados sicológicos o determinar su grado de competencia solo por el uso de algunas expresiones, como se demuestra en los siguientes extractos: "aun cuando el sujeto entrevistado presenta olvido momentáneo de la glosa apropiada" (p. 210) i "podríamos suponer que aquí cuando ella 
no responde es porque no ba entendido la pregunta" (p. 211); y "Claro, no responde no porque no supiera bablar la lengua, pues, ... la expresión kimlan tati, ... demuestra alta competencia comunicativa en lengua mapuche" (p. 211).

Finalmente, cuando afirman que "Lógicamente, estas construcciones [las del entrevistador en Gundermann et al.] perjudican la comprensión de la pregunta por parte de cualquier persona que fuese bablante de la lengua mapuche" (p. 211) terminan de despojar completamente de cualquier habilidad en mapudungun a los entrevistadores del estudio de Gundermann et al. Así, se cumple lo que propone Holliday (2015) respecto de los efectos que tiene el uso de la categoría $\mathrm{HN}$ en la creación de los otros: construir la otredad también tiene como resultado descreer de las habilidades de esos otros.

A pesar de lo anterior, la manera en que se manifiesta el nativohablantismo en este trabajo es fragmentaria y ambivalente. Los autores en ningún momento enfatizan su pertenencia a una nación o cultura mapuche, o comunidad específica. Las referencias que hacen al componente cultural que acompañaría al ser mapuche se limitan a una breve mención de la "psicología mapuche", la que no es explicada pero que daría cuenta de ciertos comportamientos de los entrevistados, que el entrevistador en el trabajo de Gundermann et al., por no ser HN, no logra captar. Finalmente, tampoco se arrogan autoridad en todos los aspectos que competen a la lengua cuando en lo relativo a su enseñanza confían en "la sapiencia del investigador" (p. 217), aunque no del profesor y tampoco en referencia a prácticas mapuche de enseñanza. En este caso, paradójicamente, no explican si ese investigador debe ser HN o no.

Curiosamente, mientras Painequeo y Quintrileo acertadamente apuntan a que la visión purista y reificada de la lengua expresada en el trabajo de Gundermann et al. enfatiza el desplazamiento ${ }^{12}$, recurren a esa misma visión idealizada de la lengua para criticar a los entrevistadores en Gundermann et al. Luego, sin embargo, destacan positivamente la incorporación efectiva por parte de hablantes de mapudungun de elementos provenientes del castellano. La discusión que presentan los autores sobre este punto es el aspecto más destacable del trabajo, el que se diluye, sin embargo, por su interés en demostrar la incompetencia de los entrevistadores en el trabajo de Gundermann et al. y por la ausencia de datos frescos y más representativos de estos fenómenos de contacto. De hecho, cuando presentan la lista de causas del desplazamiento, estas son básicamente un resumen de otros estudios, y no se desprenden de la reflexión ni investigación etnográfica propia de los autores, ni de su involucramiento con comunidades concretas.

12. Ver una crítica al respecto también en Espinoza (en prensa). 
En suma, estos autores en ningún momento logran articular la contribución del HN de mapudungun con conocimiento bibliográfico a la comprensión del desplazamiento lingüístico. Tampoco se desprenden de su texto las posibilidades de reversión de dicho desplazamiento que existirían desde esa perspectiva particular del $\mathrm{HN}$-investigador. Finalmente, cuando presentan la lista de causas del desplazamiento, no se revela en su presentación una nueva manera de entenderlas diferente a la de un investigador no-nativo.

Para Restrepo (2016, p. 64), "Ciertas experiencias o condiciones de los sujetos concretos invisten de maneras difíciles de separar (cuando no incluso de identificar) la producción misma del conocimiento". En este sentido, especialmente Painequeo y Quintrileo, desaprovechan la oportunidad de demostrar, precisamente, qué significa para los propios hablantes de una lengua indígena dar cuenta de los procesos de desplazamiento de su lengua. En otras palabras, cómo su condición y experiencia como bilingües hablantes de una lengua minorizada y miembros de una comunidad minorizada, pero también de la academia, confieren a su pensamiento límites, aperturas y, sobre todo, posibilidades de comprensión y cambio más allá de las visiones tradicionales.

\section{CATEGORIZACIONES A PRIORI VERSUS EL TRABAJO ETNOGRÁFICO}

Si bien las investigaciones de diversos aspectos relacionados con la lengua y cultura mapuche realizados por investigadores mapuche van en aumento, aún son escasos aquellos trabajos en los que estos investigadores se involucran en trabajo etnográfico de campo relativamente prolongado (más bien predomina el uso de entrevistas). Así, no existen reflexiones desde la perspectiva de estos investigadores de los desafíos y oportunidades para la investigación sociolingüística que se podrían derivar del hecho de ser hablantes de lengua indígena o miembros de una comunidad específica. El único caso al que tuve acceso y en el que se presentan reflexiones a este respecto es Relmuan (2005). Esta autora bilingüe mapudungun-castellano en ningún momento se autoidentifica como HN. Respecto del rol que jugó en su investigación el hecho de ser hablante de mapudungun plantea que

el conocimiento del mapudungun fue muy importante para mis contactos ... dado que pude realizar las conversaciones introductorias al tema y las entrevistas en mapudungun. Esto me facilitó mucho la labor y me permitió lograr la confianza y dedicación de tiempo de las personas ... o recomendarme a las demás familias para que me entreguen información (2005, p. 34). 
Nada nos puede hacer suponer que todo esto no se hubiese logrado sin ser mapuche e incluso sin hablar la lengua (JONES, 1970) ${ }^{13}$.

Por otro lado, para esta autora ser hablante de mapudungun no impidió que fuese vista por los miembros de la comunidad en que trabajó como "mapuche awingkada". En otras palabras, la condición de hablante de la lengua indígena no le otorgó membresía en esta comunidad específica ni la libró de ser asignada a cierta categoría de mapuche no pura o mapuche acbilenada. Esta situación resultó ser ventajosa en la investigación. Como explica la autora, ser considerada como ajena a la comunidad, a pesar de hablar la lengua, "facilitó mucho mi labor en el sentido de recibir una información más amplia sobre los tipos de discurso" (RELMUAN, 2005, p. 43): los entrevistados fueron más explícitos en cuanto a la información que le entregaban.

Así, mientras que el nativohablantismo apela a la ventaja derivada de la supuesta pertenencia inequívoca a una comunidad o grupo homogéneo imaginado que otorgaría tal categoría, en este caso fue la no pertenencia la que resultó beneficiosa para Relmuan como investigadora (a pesar de ser mapuche y de hablar mapudungun). No fue el estatus de insider, supuesto en los discursos nativohablantistas, sino que su calidad de extranjera en una comunidad específica lo que ayudó en su investigación.

Proponer que el trabajo de esta autora es superior solo por ser ella hablante de la lengua indígena, es ignorar y simplificar los desafíos que plantea la investigación sociolingüística etnográfica, sobre todo en comunidades indígenas rurales. Significa desconocer que el valor de la investigación radica en la exhaustividad teórica y metodológica, en la reflexividad del investigador (por ejemplo, en asumir que su calidad de hablante de mapudungun no la hacía, por defecto, parte de la comunidad a estudiar o que implicaba beneficios superiores) y en la contextualización del estudio en una comunidad específica, además de la manera en que se da cuenta de todo el proceso, incluyendo sus posibles falencias, las consecuencias para los participantes y, por lo tanto, los desafíos éticos involucrados.

\section{REFLEXIONES FINALES}

En este trabajo, he argumentado que existen similitudes entre el nativohablantismo en el contexto del inglés comolengua global y el nativohablantismo expresado en el $\mathrm{HN}$-investigador de lengua indígena. Estos dos aspectos (HN

13. Tal fue mi caso durante mi investigación doctoral. 
de lengua indígena, $\mathrm{HN}$ investigador) no han sido considerados hasta ahora en el debate en torno al nativohablantismo. También he ilustrado una paradoja en la lingüística presente en la discusión en torno a la politización de ciertas categorías. Esta paradoja ya había sido observada por Muni Toke (2014c). Según esta autora, por un lado, desde ciertos círculos de la lingüística aplicada, y debido al interés de esta por problemas lingüísticos en el mundo real y su énfasis en la producción etnográfica de conocimiento, se critican los modelos lingüísticos idealizados y abstractos implicados en el uso del concepto HN, así como sus consecuencias ideológicas y prácticas. Por otro lado, sin embargo, no pocos lingüistas continúan operando con otro tipo de idealización, la del HN puro y verdadero (O'ROURKE \& PUJOLAR, 2013) donde se ubica al HN (de lenguas minorizadas, indígenas o en peligro) y a su autenticidad en primera fila (MUNI TOKE, 2014c, pp. 87-88).

La crítica que he presentado al discurso del $\mathrm{HN}$-investigador en las secciones anteriores no va dirigida al conocimiento que de sus lenguas tienen los bilingües lengua indígena-castellano, ni a las contribuciones de (socio)lingüistas indígenas. Tampoco apunta a desmerecer las metodologías indígenas de investigación (SMITH, 2013) o a negar las contribuciones que se puedan hacer desde otras formas de conocimiento (DE SOUSA SANTOS, 2010) o que apunten a buscar autonomía intelectual (ENGLAND, 2012; SMITH, 2013) o autodeterminación cognitiva (TEILLIER et al., 2017). Creo importante subrayar, sin embargo, que ninguna de estas es la posición o perspectiva explícita o implícita de los autores y del tipo de nativohablantismo a los que me he referido en este trabajo, exceptuando tal vez a Teillier at al. (2016). En otras palabras, no parece ser que estemos en presencia de lo que Restrepo (2016) llamaría un pensamiento subalterno y propio ${ }^{14}$, ya que este último, según este autor, no está necesariamente definido ni por la pertenencia a un grupo o categoría social ni por "un sujeto definido de antemano" (p. 67), sino que por su relación con el pensamiento hegemónico y su orientación hacia la transformación social.

Mi crítica se ha limitado a explorar las manifestaciones y consecuencias de un uso particular del concepto y rasgo identificativo HN para propósitos determinados, en contextos académicos de generación y de circulación de conocimiento y en un

14. Intentos bastante interesantes en esta dirección aparecen en el libro "Mapun Kimün. Relaciones mapunche entre persona, tiempo y espacio" (BECERRA \& LLANQUINAO, 2017), donde se invita a reflexionar "desde el pensamiento propio y desde la propia lengua, con el objetivo de descolonizarse, reconstruirse y de construir nuevas respuestas -y nuevas interrogantes- frente a nuevos escenarios" (p. 15). De manera interesante para mi discusión, en este libro en ningún momento se utiliza la frase 'hablante nativo' y menos $\mathrm{HN}$-investigador, sino que se habla más bien de hablantes de mapudungun o simplemente de hablantes. 
ámbito disciplinar específico: el $\mathrm{HN}$-investigador. Mi objetivo ha sido cuestionar aquellas aseveraciones respecto de que una determinada identidad, encapsulada en un término controvertido como $\mathrm{HN}$, pueda ser utilizada como dispositivo argumental final en la discusión de fenómenos culturales y sociolingüísticos complejos que atañen a grupos humanos también complejos.

El análisis de estos casos revela la existencia de contradicciones y de una disputa intra e intergrupal por cierta legitimidad y autoridad innata que daría validez al trabajo investigativo. A fin de cuentas, como explica Bonfiglio (2010, p. 14) "The purpose of the notion of linguistic nativity, ..., is to anchor power in a certain class of speaker". Así, se crean clases de hablantes en los diferentes grupos en los que estos sujetos se movilizan. Por un lado, se crea una jerarquía de HN con diferentes niveles de competencia y con o sin formación lingüística, presentando así una posición ambivalente respecto de las contribuciones que puede hacer un $\mathrm{HN}$ al estudio de su lengua. Por otro lado, se crea una jerarquía entre investigadores HN nativos de mapudungun y los que no lo son, implicando que los primeros tendrían ciertas ventajas epistemológicas innatas.

Este último punto, sin embargo, desconoce que incluso los así llamados investigadores nativos muchas veces no pueden desprenderse de la influencia que las ideologías lingüísticas y profesionales tienen en su actividad (JACOBSHUEY, 2002; KROSKRITY, 2000; LAGOS et al., 2013). Como indica Restrepo (2016, p. 66) "los sectores subalternizados han incorporado pensamientos de los sectores dominantes inicialmente impuestos, reproduciendo concepciones del mundo y jerarquizaciones derivadas de distintos momentos históricos y sistemas de dominación". Por ejemplo, para el caso de las lenguas minorizadas, O’Rourke y Pujolar (2013) explican que los movimientos de revitalización han apelado a las mismas ideologías lingüísticas dominantes que moldearon el pensamiento Europeo, incluyendo la del $\mathrm{HN}$. Apelar, entonces, al $\mathrm{HN}$-investigador contribuye a perpetuar el aparataje teórico 'occidental' que tanto se suele criticar, y a dar continuidad a "la máquina de binarismos propia de la modernidad eurocéntrica" (RESTREPO, 2016, p. 68). En este sentido, el ejercicio de la reflexividad epistemológica es necesario tanto para investigadores nativos como no-nativos (SALÖ, 2018).

Al HN representado por estos estudios también se le podría aplicar la crítica que hace Olate (2017) al intento de algunos lingüistas por recurrir a una epistemología del HN de mapudungun. Olate $(2017$, p. 256) se refiere a estos intentos como

una idealización de la noción de hablante, el autor no explicita claramente a qué se refiere cuando usa este concepto. Desde una mirada atómica, basada en la competencia lingüístico- 
comunicativa, el hablante [nativo] ... parece ser un monolingüe; sin embargo, en la situación de contacto, estamos ante un hablante bilingüe. Por otro lado, la noción de epistemología del hablante parece dejar de lado las complejidades sociológicas, ideológicas, axiológicas, epistemológicas, antropológicas e históricas contenidas en los hablantes para dar paso a un esencialismo anacrónico.

La recepción acrítica de este tipo de nativohablantismo puede ser perjudicial a nivel disciplinar y de generación de conocimiento. En primer lugar, significaría aceptar que este $\mathrm{HN}$ de lengua indígena es hablante de la lengua indígena, entendida como código uniforme, idealizado y compartido por un grupo territorializado también homogéneo e idealizado (y monolingüe), lo que equivaldría a desconocer la compleja distribución geográfica de los mapuche en Chile, las diferentes trayectorias sociolingüísticas por las que han transitado, y la larga historia de contacto mapudungun-castellano. En segundo lugar, contribuiría a instalar la noción de que la presencia de un factor identitario determinado, más que el trabajo etnográfico, implica algún tipo de capacidad especial o sello de validación ${ }^{15}$ para el estudio de problemas sociolingüísticos complejos como el desplazamiento lingüístico. El trabajo de Relmuan (2005) ilustra la manera en que la labor etnográfica supera las idealizaciones de categorías a priori. Apelar al HNinvestigador solo contribuirá a acentuar el divorcio existente entre investigadores y las comunidades que se pretende describir y comprender, lo que redunda en que las metodologías utilizadas y el tipo de conocimiento producido pueden no dar cuenta adecuadamente de las complejidades y potencialidades presentes en comunidades indígenas en Chile.

Este debate, sin embargo, no es solo disciplinar y puede tener ramificaciones importantes para la situación de lengua minorizada y en desplazamiento como el mapudungun. Como explica Kabel (2009, p. 17) "While the discourses of nativespeakerism are disciplinary constructions, their consequences are, nonetheless, very real. Native-speakerism produces realities of exclusion, discrimination and rationalizations for intervention and 'cultural correction'". En este sentido, estos discursos académicos también pueden permear iniciativas concretas de promoción de lenguas indígenas. Como se ha demostrado para otros contextos de lenguas minorizadas y de revitalización lingüística, las distinciones y jerarquías que se establecen entre hablantes nativos y hablantes no-nativos, bilingües emergentes o nuevos hablantes pueden conducir a tensiones respecto de la autenticidad, precisión y propiedad del lenguaje, así como del control que se ejerza sobre este, dificultando

15. Véase también al respecto la discusión en Kroskrity 2000 en torno al rol que se asignaba en la antropología norteamericana al llamado antropólogo nativo 
iniciativas en las que participan multiplicidad de actores con, por ejemplo, diferentes tipos de competencia en una lengua (CORONEL-MOLINA, 2015; COSTA, 2015; DE KORNE, 2017; NIC FHLANNCHADHA \& HICKEY, 2016; HORNSBY, 2015; O'ROURKE \& PUJOLAR, 2013; O'ROURKE \& WALSH, 2015; ZAVALA, 2015, 2018).

Si bien no se puede desconocer que los discursos (académicos y no académicos) en torno a las lenguas minorizadas, la discusión de sus procesos sociolingüísticos, así como los proyectos de mantención y revitalización son también espacios de disputa ideológica y política (COSTA \& GASQUET-CYRUS, 2013; COSTA, 2015), la imposición y aceptación acrítica de categorías tales como $\mathrm{HN}$-investigador no solo puede redundar en dificultades para comprender las complejas realidades sociolingüísticas de las lenguas indígenas en Chile, al atrasarnos aún más en el desarrollo del trabajo etnográfico, sino que también puede ser contraproducente al momento de llevar adelante procesos que contribuyan a la promoción de dichas lenguas. A fin de cuentas, apelar al HN es reforzar la influencia de un pensamiento hegemónico y contribuir al status quo tanto en la investigación lingüística como fuera de ella .

\section{REFERENCIAS}

ADLEY-SANTAMARIA, B. (1997). White Mountain Apache language: issues in language shift, textbook development, and native speaker-university collaboration. En: Reyhner, J. Teaching Indigenous Languages. Selected Papers from the Annual Symposium on Stabilizing Indigenous Languages. Flagstaff, AZ: Northern Arizona University, pp. 129-143.

ÁLVAREZ-SANTULLANO, P.; FORNO, A.; RISCO DEL VALLE, E. (2015). Propuestas de grafemarios para la lengua mapuche: desde los fonemas a las representaciones político-identitarias. Alpha, 40, pp. 113-130.

AMEKA, F. K. (2006). Real descriptions: Reflections on native speaker and non-native speaker descriptions of a language. En: Ameka, F. K.; Dench, A.; Evans, N. (Eds.), Catching Language: The Standing Challenge of Grammar-writing. Mouton: Berlin, pp. 69-112.

ANEJA, G. (2014). Disinventing and reconstituting native speaker ideologies through the classroom experiences of international TESOL students. Working Papers in Educational Lingusitics, 29, 1, pp. 23-39.

BECERRA, P. (2017). Mapudungun y tipología de los eventos de movimiento. Lenguas y Literaturas Indoamericanas, 19, 1, pp. 118-140. 
BECERRA R.; LLANQUiNAO, G. (eds.). (2017). Mapun Kimün. Relaciones mapunche entre persona, tiempo y espacio. Santiago: Ocho Libros.

BELTRÁN, R. (2000). El 'hablante nativo’ de la lengua meta: ćqué importancia tiene para la enseñanza de la L2. Elia: Estudios de Lingüística Inglesa Aplicada 1, pp. 9-22.

BLOMMAERT, J. (2017). 'Home language': some questions. Tilburg Papers in Culture Studies, 183.

BLOMMAERT, J. \& RAMPTON, B. (2011). Language and superdiversity: A position paper. Working Papers in urban Language \& Literacies, 70.

BONFIGLIO, T. (2010). Mother tongues and nations: The invention of the native speaker. Berlin \& New York: Walter de Gruyter

BOURDIEU, P. \& THOMPSON, J. (1991). Language \& Symbolic Power. Harvard: Harvard University Press.

BRAINE, G. (2010). Nonnative speaker English teachers: Research, pedagogy, and professional growth. New York: Routledge

CAMBIER-LANGEVELD, T. (2010). The role of linguists and native speakers in language analysis for the determination of speaker origin. International Journal of Speech, Language \& the Law, 17, 1, pp. 67-93.

CANAGARAJAH, S. (1999). Interrogating the "native speaker fallacy": Non-linguistic roots, non-pedagogical results. En: Braine, G (ed.), Non-native educators in English language teaching. Mahwah, NJ: Lawrence Erlbaum Associates, Publishers, pp. 77-92.

CANAGARAJAH, S. (2007). Lingua franca English, multilingual communities, and language acquisition. The modern language journal, 91, pp. 923-939.

CATRIQUIR, D. (2007). Mapunzugun: Una contribución al reposicionamiento de la denominación de la lengua y la sociedad mapunche. En: Durán, T.; Catriquir, D; Hernández, A. (eds.), Patrimonio Cultural Mapunche, V. I, pp. 35-51.

CHIODI, F. \& LONCON, L. (1999). Crear nuevas palabras. Innovación y expansión de los recursos lexicales del mapuzugun. Temuco: UFRO - CONADI.

COOK, V. (1999). Going beyond the native speaker in language teaching. TESOL quarterly 33, 2, pp. 185-209. 
CORONEL-MOLINA, S. (2015). Language ideology, policy and planning in Peru. Buffalo, NY: Multilingual Matters.

COSTA, J. (2015). New speakers, new language: on being a legitimate speaker of a minority language in Provence. International Journal of the Sociology of Language 231, pp. 127-145.

COSTA, J. \& GASQUET-CYRUS, M. (2013). What is language revitalization really about? Competing language revitalization movements in Provence. En: Jones, M. \& Ogilvie, S. (eds.), Keeping languages alive: Documentation, pedagogy and revitalization. Nueva York: Cambridge University Press, pp. 212-224.

DAVIES, A. (1991). The native speaker in applied linguistics. Edinburgh: Edinburgh University Press.

DAVIES, A. (2003). The native speaker: myth and reality. Clevedon: Multilingual matters.

DE KORNE, H. (2017). The multilingual realities of language reclamation: Working with language contact, diversity, and change in endangered language education. Language Documentation and Description, 14, pp. 111-135.

DE SOUSA SANTOS, B. (2010). Descolonizar el saber, reinventar el poder. Montevideo: Ediciones Trilce.

DOBRIN, L.; AUSTIN, P.; NATHAN, D. (2009). Dying to be counted: The commodification of endangered languages in documentary linguistics. En: Austin, P. (ed.), Language documentation and description, volume 6. London: SOAS, pp. 37-52

DOERR, N. (ed.). (2009). The native speaker concept: Ethnographic investigations of native speaker effects. Berlín: Walter de Gruyter.

DURÁN, T., \& RAMOS, N. (1989). Interacción mapudungun-castellano vinculada a contextos educacionales en una población mapuche rural. Lenguas Modernas, 16, pp. $97-113$

ENGLAND, N. (2012). The Study of Indigenous Languages in Latin America. LASAForum XLIIII, 1, pp. 11-14.

ESPINOZA, M. (2015). El hablante nativo como modelo de norma pragmática: su caracterización e implicancias en pragmática de interlengua. Onomázein, 32, pp. 212-226.

ESPINOZA, M. (en prensa). Ideologías lingüísticas en el estudio de la 'competencia en lengua índigena’ en chile. Implicancias teóricas y metodológicas. Estudios Filológicos. 
EVANS, N. (2001). The last speaker is dead; long live the last speaker. In: Newman, P. \& Ratliff, M. (eds.), Linguistic fieldwork. Cambridge: Cambridge University Press, pp. $250-81$

FALLAS, C. (2016). Challenging the Monolingual Bias in EFL Programs: Towards a Bilingual Approach to L2 Learning. Revista de Lenguas Modernas, 24, pp. 249-266.

GUNDERMANN, H.; CANIHUAN, J.; CLAVERÍA, A.; FAÚNDEZ, C. (2009). Permanencia y Desplazamiento, Hipótesis acerca de la vitalidad del mapuzugun. RLA 47, pp. 37-60.

HALE, K. (1972). A new perspective on American Indian Linguistics." With appendix by Albert Alvarez. En: Ortiz, A. (ed.), New perspectives on the Pueblos. University of New Mexico Press, pp. 87-103.

HALE, K.; KRAUSS, M.; LUCILLE J. W.; YAMAMOTO, A.; CRAIG, C.; MASAYESVA, L.; ENGLAND, N. (1992). Endangered languages. Language 68, pp. 1-42

HENRÍQUEZ, M. (2017). Aproximaciones a la fonología del Chedungun: un estudio exploratorio en niños Pewenches del Alto Bío-Bío. Nueva revista del Pacífico 66, pp. 99-114.

HENRÍQUEZ, M., \& SALAMANCA, G. (2012). Rasgos prominentes de la fonología segmental del chedungun hablado por escolares del Alto Bío-Bío. Alpba (Osorno), 34, pp. $153-171$.

HIMMELMANN, N. (2006). Language documentation: What is it and what is it good for. En: Gippert, J.; Himmelmann, N.; Mosel, U. (eds.), Essentials of Language Documentation. Mouton de Gruyter, pp. 1-30.

HOLLIDAY, A. (2005). The struggle to teach English as an international language. Oxford: Oxford University Press

HOLLIDAY, A. (2006). Native-speakerism. ELT journal, 60, 4, pp. 385-387.

HOLLIDAY, A. (2015). Native-speakerism: Taking the concept forward and achieving cultural belief. En: Swan, A.; Aboshiha, P; Holliday, A. (eds.), (En)countering nativespeakerism. London, England: Palgrave Macmillan, pp. 11-25.

HORNSBY, MI. (2015). "The "new" and "traditional" speaker dichotomy: Bridging the gap." International Journal of the Sociology of Language 231, 1, pp. 107-125. 
JACOBS-HUEY, L. (2002). The natives are gazing and talking back: Reviewing the problematics of positionality, voice, and accountability among "native" anthropologists. American Antbropologist, 104, 3, pp. 791-804.

JONES, D. J. (1970). Towards a native anthropology. Human Organization, 29, 4, pp. 251-259.

KABEL, A. (2009). Native-speakerism, stereotyping and the collusion of applied linguistics. System, 37, 1, pp. 12-22.

KRAVCHENKO, A. V. (2010). Native speakers, mother tongues and other objects of wonder. Language Sciences, 32, 6, pp. 677-685.

KROSKRITY, P. (2000). Language Ideologies in the Expression and Representation of Arizona Tewa Ethnic Identity. En: Kroskrity, P. (ed.), Regimes of Language: Ideologies, Polities, and Identities. Santa Fe, New Mexico: School of American Research Press.

LAGOS, C.; ESPINOZA, M.; ROJAS, D. (2013). Mapudungun according to its speakers: Mapuche intellectuals and the influence of standard language ideology. Current Issues in Language Planning 14, pp. 403-418.

LARA MILLAPÁN, M. (2012). Aprender a leer y escribir en lengua mapudungun, como elemento de recuperación y promoción de la cultura mapuche en la sociedad del siglo XXI. Tesis de cotorado. Universitat Autònoma de Barcelona, Departament de Didàctica de la Lengua, de la Literatura i de les Ciències Socials

LIDDICOAT, A. (2016). Native and non-native speaker identities in interaction: Trajectories of power." Applied Linguistics Review 7, 4, pp. 409-429.

LOERA, J. (2018). Pluralidad de voces en los discursos del bienestar: Una experiencia etnográfica reflexiva. Chungará (Arica), 50, 3, pp.513-522

LONCON, E. (2017). El poder creativo de la lengua Mapudungun y la formación de neologismos. Tesis de doctorado. Leiden University

LOWE, R. (2016). Reflections on Thomas Paikeday's The Native Speaker Is Dead!(1985). Studies in English Language and Literature .22, pp. 24-36.

LOWE, R. J. \& KICZKOWIAK, M. (2016). Native-speakerism and the complexity of personal experience: A duoethnographic study. Cogent Education, 3(1).

MAY, S. (2013). The multilingual turn: Implications for SLA, TESOL, and bilingual education. New York, NY: Routledge. 
MUNI TOKE, V. (2011). Deontological issues, language ideologies and reflexivity in linguistics. Native competence vs scientific knowledge? Pragmatics and Society 2, 2. Amsterdam, Philadelphia: John Benjamins, pp. 205-233.

MUNI TOKE, V. (2014c). Native speaker: from idealization to politicization. Histoire, Epistémologie, Langage, 35, 2, pp. 69-93.

MOORE, R. E.; PIETIKÄINEN, S.; BLOMMAERT, J. (2010). Counting the losses: Numbers as the language of language endangerment. Sociolinguistic Studies, 4, 1, pp. 1-26.

MOULIAN, R., \& CATRILEO, M. (2013). Kamaska, kamarikun y müchulla: préstamos lingüísticos y encrucijadas de sentido en el espacio centro y sur andino. Alpha (Osorno), (37), pp. 249-263.

NAQILL, V. (2016). https://www.elciudadano.cl/pueblos/no-he-visto-otros-movimientosen-el-continente-que-utilicen-la-calle-para-reivindicar-su-lengua/04/01/

NIC FHLANNCHADHA, S. \& HICKEY, T.M. (2016). Minority language ownership and authority: perspectives of native speakers and new speakers. International Journal of Bilingual Education and Bilingualism, pp. 1-16.

NANCULEF, J. (2016). Tayiñ Mapuche Kimün. Epistemología Mapuche-Sabiduría y Conocimientos. Santiago: Universidad de Chile.

OLATE, A. (2017). Más allá del estado de vida de las lenguas... elementos para el diagnóstico sociolingüístico de la dinámica interactiva del contacto mapuzugun/castellano. Alpha (Osorno), 45, pp. 255-272.

O'ROURKE, B. \& PUJOLAR, J. (2013). From native speakers to "new speakers"problematizing nativeness in language revitalization contexts. Histoire Épistémologie Langage, 35, 2, pp. 47-67.

O’ROURKE, B.; PUJOLAR, J.; RAMALLO, F. (2015). Introduction to special issue 'New speakers of minority languages: The challenging opportunity'. International Journal of the Sociology of Language 231, pp. 1-20.

O’ROURKE, B. \& WALSH, J. (2015). New Speakers of Irish: Shifting Boundaries Across Time and Space. International Journal of the Sociology of Language 231, 1, pp. 63-83. 
ORTEGA, L. (2013). Ways forward for a bi/multilingual turn in SLA. In: May, S. (ed.) The multilingual turn: Implications for SLA, TESOL and bilingual education. Newy York: Routledge, pp. $32-53$

PAIKEDAY, T. M. (1985a). The native speaker is dead! Toronto: Paikeday Publishing.

PAIKEDAY, T. M. (1985b). May I kill the native speaker? TESOL Quarterly, 19, 2, pp. 390-395.

PENNYCOOK, A. (1990). Towards a Critical Applied Linguistics for the 1990s. Issues in Applied Linguistics, 1, 1, pp. 8-28.

PENNYCOOK, A. (2001). Critical applied linguistics: A critical introduction. Routledge.

PAINEQUEO, J. \& QUINTRILEO, E. (2010). Algunas causas en la interrupción hacia la Transmisión y uso de la Lengua mapuche. Lenguas y Literaturas Indoamericanas, (14).

PAINEQUEO, J., \& QUINTRILEO, E. (2015). Algunas causas que podrían estar incidiendo en el eventual debilitamiento de la vitalidad y posible desplazamiento de la lengua mapuche por el castellano en Chile. Onomázein, 31(1), pp. 205-218.

PILLER, I. (2001). Who, if anyone, is a native speaker? Anglistik. Mitteilungen des Verbandes Deutscher Anglisten, 12, pp. 109-121.

RAMPTON, B. (1990). Displacing the 'native speaker': expertise, affiliation, and inheritance. ELT Journal, 44, 2, pp. 97-101,

RELMUAN, M. (2005). El mapuche, el aula y la formación docente. Vol. 7. La Paz: Plural Editores.

RESTREPO, E. (2016). Descentrando a Europa: aportes de la teoría postcolonial y el giro decolonial al conocimiento situado. Revista Latina de Sociología, 6, 1, pp. 60-71

RUMIAN, S. (2011). Futawillimapu.org. Disponible en: http://www.futawillimapu.org/ pub/2011/PESPI/PESPI 2011 - Che Sungun - S01.pdf

SALÖ, L. (2018). Seeing the point from which you see what you see: An essay on epistemic reflexivity in language research. Multilingual Margins: A journal of multilingualism from the periphery, 5, 1, pp. 24-24.

SMITH, L. T. (2013). Decolonizing methodologies: Research and indigenous peoples. Zed Books Ltd.. 
SWAN, A.; ABOSHIHA, P.; HOLLIDAY, A. (Eds.). (2015). (En)countering native-speakerism: Global perspectives. Houndmills: Palgrave Macmillan.

TEILLIER, F. (2013). Vitalidad lingüística del mapudungun en Chile y epistemología del hablante. RLA. Revista de lingüística teórica y aplicada, 51, 1, pp. 53-70.

TEILLIER, F.; LLANQUINAO, G.; SALAMANCA, G. (2016). De qué hablamos cuando hablamos de etnolingüística: bases teórico-metodológicas para un trabajo con el mapunzugun. RLA. Revista de lingüística teórica y aplicada, 54, 2, pp. 137-161.

TEILLIER, F.; LLANQUINAO, G.; SALAMANCA, G. (2017). Autodeterminación cognitiva y mapun kimün. En: Becerra R., y G. Llanquinao (eds.),Mapun Kimün. Santiago: Ocho Libros, 25-39.

TEILliER, F.; LLANQUINAO, G.; SALAMANCA, G. (2018). Epistemología de la lengua mapunzugun: definición conceptual de Küpalme, Rakizuam y Güxam. Papeles de trabajo - Centro de Estudios Interdisciplinarios en Etnolingüística y Antropología Socio-Cultural, 36, pp. 100-122.

VIÁFARA, J. J. (2016). I'm Missing Something": (Non) Nativeness in Prospective Teachers as Spanish and English Speakers. Colombian Applied Linguistics Journal, 18, 2, pp. 11-24.

WATERS, A. (2007). Native-speakerism in ELT: Plus ça change...? System, 35, 3, pp. 281 292.

WAWRZYNIAK, J. K. (2010). Native speakers, mother tongues and natural semantic metalanguages. Language Sciences, 32, 6, pp. 648-670.

WELLS, J. \& PAPPENHEIM, R. (1996) El hablante nativo: un término y concepto que necesita ser recontextualizado. Forma y Función 9, pp. 39-48.

WIDDOWSON, H. G. (2012). ELF and the inconvenience of established concepts. Journal of English as a Lingua Franca 1, 1, pp. 5-26.

WITTIG, F. (2009). Desplazamiento y vigencia del mapudungún en Chile: un análisis desde el discurso reflexivo de los hablantes urbanos. RLA. Revista de lingüistíca teoríca y aplicada, 47, 2, pp. 135-155.

WITTIG, F. (2011). Adquisición y transmisión del mapudungún en hablantes urbanos. Literatura y lingüística, 23, pp. 193-211. 
ZAVALA, V. (2015). "It will emerge if they grow fond of it": Translanguaging and power in Quechua teaching. Linguistics and Education 32, pp. 16-26.

ZAVALA, V. (2018). Language as social practice: deconstructing boundaries in intercultural bilingual education. Trabalbos em Linguística Aplicada, 57, 3, pp. 1313-1338.

Recebido: 5/03/2019

Aceito: 5/07/2019

Publicado: 1/08/2119 